\title{
Design of Application Architecture for Spatial Information Based Volcanic Disaster Response System ${ }^{1}$
}

\author{
J. Youn ${ }^{\text {a }}$, T. Kim ${ }^{\text {a }}$ D. Kim ${ }^{\text {a }}$, G. Kim ${ }^{\mathrm{b}}$
${ }^{\text {a }}$ ICT Convergence and Integration Research Institute, Korean Institute of Civil Engineering and Building Technology, Korea - (younj, kth, dusikkim)@kict.re.kr

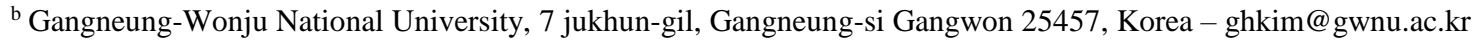

\author{
Commission VIII, WG V III/1
}

KEY WORDS: volcanic disaster, spatial information based response system, application architecture

\begin{abstract}
:
The Korean Government has executed the research project named "The development of volcanic disaster response system". The phase I of this project was completed at 2015. From the year 2015, phase II of the project has been executed. The goal of the phase II is advancing the system which was developed at phase I. This paper deals with the design of application architecture for spatial information based volcanic disaster response system. First, we analyses application architecture of phase I system. Next, users' requirements are analysed. Main requirements are three. One is extending spatial scope for volcanos. Another is developing realtime processing model for direct disaster. The other is multi-scenarios based processing. User's requirements are stepped down to variable levels to adjusted application architecture in the system. Finally, we design altered application architecture comparing with architecture of phase I system and users' requirements. The results of this research could be used for detail design of technical architectures (DA/SA/HA/NA).
\end{abstract}

\section{INTRODUCTION}

The Republic of Korea has been developing technology for building a Volcanic Disaster Response System (VDRS) since 2014 through two stages to respond to volcanic disasters. Although the Korean Peninsula is classified as a safe area from volcanic disasters, recent observations and studies indicate that the Korean Peninsula is no longer a safe area for volcanic disasters (Youn et al., 2016; Youn and Kim, 2016). Accordingly, the government has been developing the IT-based system construction technology that predicts and responds to the damage of the volcanic disasters since 2014 in the first stage. Kim and Youn (2014) proposed the construction plan of the first stage VDRS. In this article, we derive the task process responding to volcanic disasters, and present system concept diagram, application architecture, and required spatial information. The structure of the platform architecture for integrated VDRS operation was proposed by Kim and Choi (2013). VDRS can visualize diffusive volcanic ashes in two dimensions and three dimensions based on spatial information. Youn et al. (2016) and Youn and Kim (2016) presented three methods for three-dimensional visualization of diffusive volcanic ashes (Youn et al., 2016; Youn and Kim, 2016). This system was named VDRS V.1.0 and is currently being employed by the government for volcanic disaster responses. Since then, there has been a demand for system upgrading, and since 2015, VDRS V2.0 has been developed as a second stage research project.

To upgrade the system, it is necessary to reengineer the architecture before building the system. Kim and Kang (2009) demonstrated the effectiveness of the functional scalability of the reengineer method by comparing the method of reengineering and building the architecture and the method of building it without reengineer. Bengtsson and Bosh (1998) derive the architectural structure and system definition by reengineering the architecture of the software in a manner that changes the design while measuring the quality based on the scenario. Traditional reengineer was based on grammar analysis of source code, while Cha et al. (2003) strived to reengineer by adding design patterns for domain semantics and roles.

In this paper, we reengineer the manager-level application architecture for solving systematic management problems occurring due to upgrading VDRS. The application architecture is characterized by the identification and definition of activities that derive the information needed for the task and manipulate it. The studies that designed the application architecture for the system construction by analyzing the administrative tasks such as the response to the volcanic disasters, include the application architecture derivation for utilization of spatial information linkage in transportation administration work (Youn, 2008) and the application architecture derivation for utilization of spatial information for occupation related administration work(Youn and Kim, 2015). The system architecture for VDRS upgrading has been proposed by Kim et al. (2015). In the previous study, work flow and connection diagram, system concept diagram, and technical architecture for system upgrading were presented. In this article, we advance the relevant studies to analyze the application architecture and user requirements of VDRS V1.0, reengineer the application architecture for VDRS V2.0 construction, and derive application system structure and application function description.

1 This paper is an enriched and revised version of a paper presented at the Journal of the Korean Society for Geospatial Information System, 2018 (in process) 


\section{ANALYSIS OF EXISTING APPLICATION ARCHITECTURE AND USER'S REQUIREMENTS}

The application architecture designed in VDRS V1.0 is designed as a scenario-oriented architecture. The structure diagram of the VDRS V1.0 application system is shown in Fig. 1. When the volcano erupts, rapid and accurate prediction on diffusion and damage is crucial. As shown in Fig. $1 \mathrm{P}$, in case of the volcanic precursor phenomenon, the scenario which is most similar to the current situation is selected and used from the precalculated scenarios, and when the eruption starts, the most accurate damage prediction result is derived through real-time simulation [1]. In both scenario inquiry and real-time simulations, damage prediction by sector/region is represented by a two-dimensional damage thematic map (Fig. $1 \mathrm{Dm}$ ), and diffusion prediction is represented by a three-dimensional damage thematic map (Fig. 1 Df). After the diffusion prediction, the response step is selected and the response task is performed as simultaneously propagating the situation (Fig. 1R). This scenario-based architecture has the advantage of being performed in the order of tasks performed by the user, while the unskilled user has a difficulty in finding a target function due to the structure. As shown in Fig. 1, this architecture is very complex and needs to be simplified to a task-oriented architecture.

To improve the accuracy of the analysis, there is a user requirement for variations in the ash diffusion model and the similar scenario search enhancement considering the meteorological fields. In VDRS V1.0, FALL3D was used as a diffusion model of volcanic ash. To improve the accuracy of the diffusion model, the analysis of various models (FALL3D, PUFF, LADAS-VA, CMAQ) and the analysis of the ensemble model using all the models should be added. In VDRS V1.0, the variables used to search for similar scenarios are the eruption type and eruption date of the volcano. However, because the diffusion of volcanic ash is necessary to consider the meteorological field, the meteorological field should be included as an input parameter. Moreover, there was a user requirement that different possible scenarios rather than only one similar scenario should be provided.

In VDRS V1.0, the target volcano is Mount Paektu, and the target disaster of real-time simulation is only volcanic ash. The need to respond to the eruption of volcanoes in East Asia (China, Japan, etc.), which could affect the Korean peninsula, was raised. As the target volcanoes increase, the application architecture must be further changed. Furthermore, the corresponding architecture needs to be changed according to the demand on functional addition of real-time simulation for pyroclastic flow, volcanic mudflow, and, and volcanic floods.

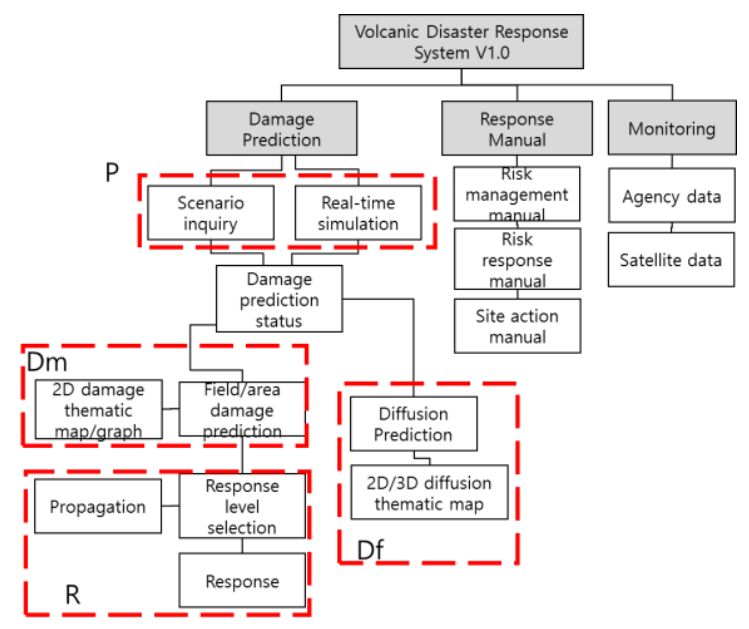

Figure 1. Application system structure for VDRS Version 1

\section{ARCHITECTURE REENGINEERING}

In the previous chapter, we analyzed user requirements for VDRS V2.0. This chapter divides requirements into three categories and discusses architectural reengineer for each category. The results of the reengineer are represented by the application architecture structure and the application functional description.

\subsection{Business oriented architecture reengineering}

The first user requirement is "scenario-oriented to task-oriented architecture reengineer". The existing system consists of scenarios-oriented architecture, which is a sequence of tasks, and has a complicated structure inappropriate for the use of the unskilled person. In analyzing the existing architecture, the task can be roughly divided into three types: real-time volcanic disaster prediction, situation response, and eruption scenarios. Thus, it is necessary to raise the task to architecture level 1 and the function of the corresponding lower level should be reconstructed. The structure of the application system of the reengineered VDRS V2.0 is shown in Fig. 2. Fig. 2 shows that real-time volcanic disaster prediction, situation response, and eruption scenarios were deployed at level 1. Compared to Fig. 1 , the $\mathrm{R}$ part is separated as the situation response, and the $\mathrm{P}$ part is divided into the real-time volcanic disaster prediction and the eruption scenarios, which correspond to the subfunctions of Dm and Df, respectively. The response manual and monitoring function do not require reengineer. 


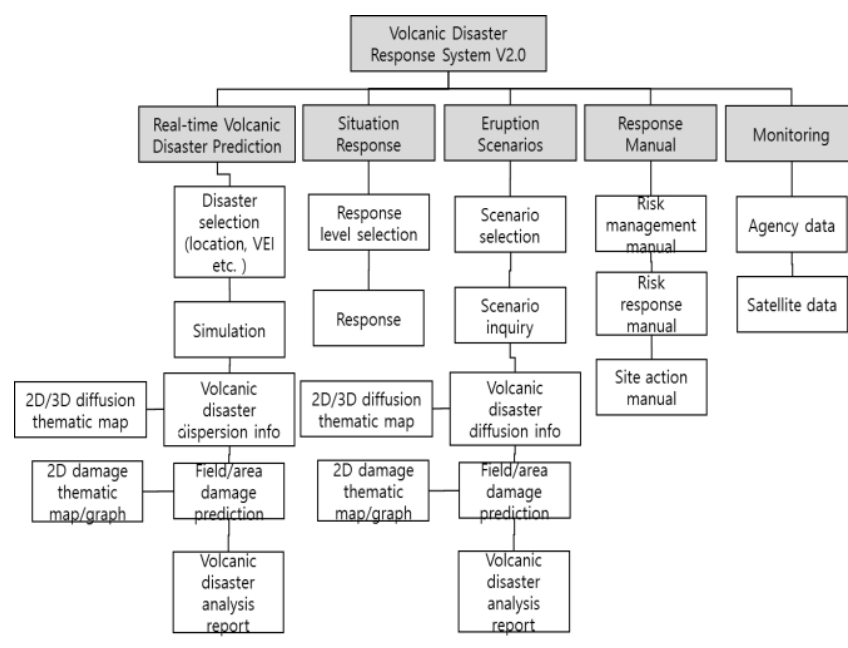

Figure 2. Application system structure for VDRS Version 2

The reengineered real-time volcanic disaster prediction function (Level 1) has disaster selection, simulation, volcanic disaster dispersion info, field/area damage prediction, and volcanic disaster analysis report as sub-function (Level 2). The disaster selection has the function of inputting eruption information and disaster type as sub-function (Level 3). The eruption information function can be explained by the function of selecting and inputting the position of eruption volcano, date and time of eruption, crater elevation, eruption plume, VEI index, eruption duration, and the like. Type of disasters is the function of selecting and inputting volcanic ash, volcanic floods, pyroclastic flow, and volcanic mudflow. In VDRS V1.0, only real-time simulation of volcanic ash was performed. In VDRS V2.0, real-time simulation function of volcanic floods, pyroclastic flow, and volcanic mudflow is added. The detail will be discussed in Section 3.3. Diffusion information and damage prediction (Level 2) are both sub-functions (Level 3) and have a function generating two-dimensional and three-dimensional thematic maps. Diffusion information can be explained by the regional diffusion by each disaster, and the damage prediction can be explained by the thematic maps and the graphical representation of the expected damage by disaster in each sector (health, industry, social infrastructure, environment, etc.). Table 1 shows the application function description for real-time volcanic disaster prediction. The disaster type function (Level 3 ) in Table 1 has sub-functions for accuracy enhancement, which will be described in detail in Section 3.2.

Figure 3 shows the examples of selecting the target area. The region in right map of the Figure 3 is sub-area of the bold region in left map of the Figure 3. The predicted damage of agricultural fields denoted by graph is shown in Figure 4. Figure 5 shows the example of time-series volcanic ash diffusion 2D map. 3D map with "Semi-transparent Volcanic Ash Plane" technique in VDRS is shown in Figure 6.

\begin{tabular}{|l|l|l|l|}
\hline Level 1 & Level 2 & Level 3 & Description \\
\hline $\begin{array}{l}\text { Real-time } \\
\text { volcanic } \\
\text { disaster } \\
\text { prediction }\end{array}$ & $\begin{array}{l}\text { Disaster } \\
\text { selection }\end{array}$ & $\begin{array}{l}\text { Eruption } \\
\text { information }\end{array}$ & $\begin{array}{l}\text { Selecting } \\
\text { eruption info: } \\
\text { location, date, } \\
\text { crater elevation, } \\
\text { ash plume, } \\
\text { VEI, eruption } \\
\text { time }\end{array}$ \\
\hline
\end{tabular}

\begin{tabular}{|c|c|c|}
\hline & $\begin{array}{l}\text { Disaster } \\
\text { type }\end{array}$ & $\begin{array}{l}\text { Selecting } \\
\text { disaster type: } \\
\text { volcanic ash, } \\
\text { volcanic flood, } \\
\text { Pyroclastic } \\
\text { flow, Volcanic } \\
\text { mudflow }\end{array}$ \\
\hline \multirow{2}{*}{$\begin{array}{l}\text { Diffusion } \\
\text { information }\end{array}$} & $\begin{array}{l}2 \mathrm{D} \\
\text { thematic } \\
\text { map }\end{array}$ & $\begin{array}{l}\text { Generating 2D } \\
\text { diffusion } \\
\text { thematic map }\end{array}$ \\
\hline & $\begin{array}{l}\text { 3D } \\
\text { thematic } \\
\text { map }\end{array}$ & $\begin{array}{l}\text { Generating 3D } \\
\text { diffusion } \\
\text { thematic map }\end{array}$ \\
\hline \multirow{2}{*}{$\begin{array}{l}\text { Damage } \\
\text { prediction }\end{array}$} & $\begin{array}{l}2 \mathrm{D} \\
\text { thematic } \\
\text { map }\end{array}$ & $\begin{array}{l}\text { Generating 2D } \\
\text { damage } \\
\text { prediction } \\
\text { thematic map }\end{array}$ \\
\hline & $\begin{array}{l}\text { 3D } \\
\text { thematic } \\
\text { map }\end{array}$ & $\begin{array}{l}\text { Generating 3D } \\
\text { damage } \\
\text { prediction } \\
\text { thematic map }\end{array}$ \\
\hline $\begin{array}{l}\text { Analysis } \\
\text { Report }\end{array}$ & & $\begin{array}{l}\text { Generating } \\
\text { analysis report }\end{array}$ \\
\hline
\end{tabular}

Table 1. Description of application function for real-time volcanic disaster prediction

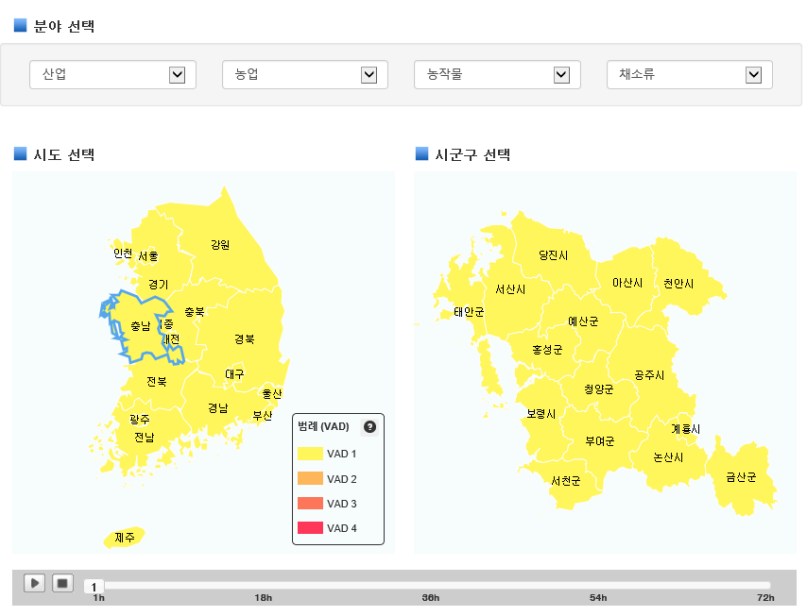

Figure 3. The examples of selecting target area

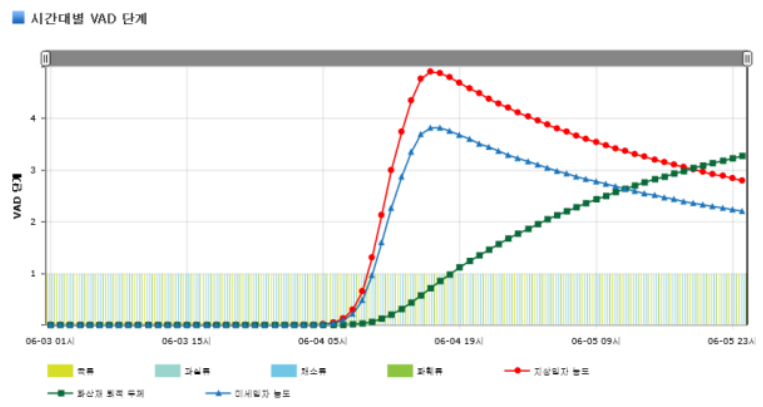

Figure 4. The examples of time-series damage prediction for agriculture field 


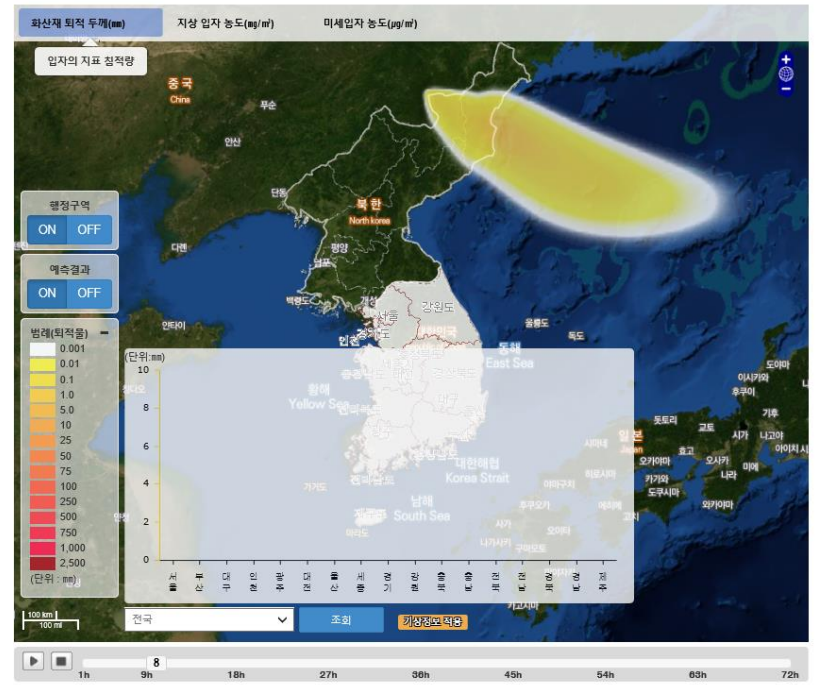

Figure 5. The example of time-series volcanic ash diffusion 2D map

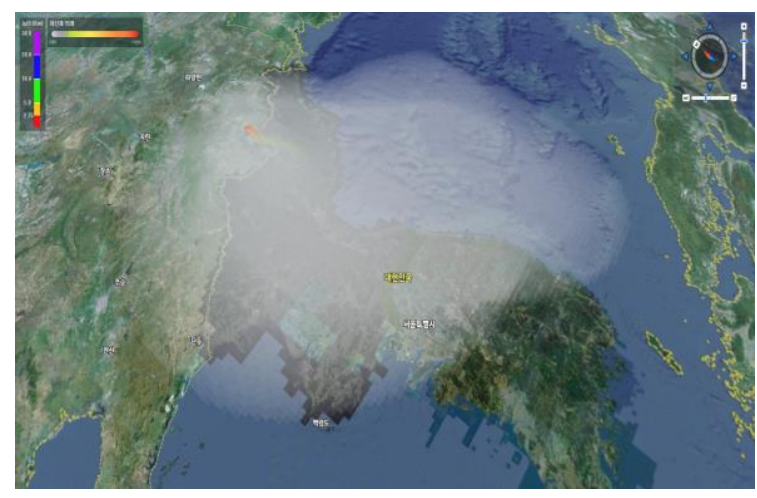

Figure 6. The example of volcanic ash diffusion 3D map with "Semi-transparent Volcanic Ash Plane" technique (Youn et al., 2016)

The situation response function (Level 1) consists of Response level selection function and Response function as sub-function (Level 2). Response level can be divided into normal, interest, attention, alert, severe, and restoration stages. Responses to normal stage include system and emergency network checks. At the interest stage, responses consist of the reception and monitoring of the eruption information, the operation of the response system, and the instructions to municipalities to implement the necessary steps at the interest stage. At the attention stage, disaster status monitoring, crisis alert notification, operation of the Central Disaster Safety Headquarters, and emergency measures for hazardous facilities in the affected areas are added. At the alert stage, the collection and dissemination of disaster information, issuance of crisis alarms, direction/requests for municipal damage reports, and preparations for the declaration of disaster are added. At the severe stage, collection of disaster status information, the construction and operation of the emergency rescue control unit, and the announcement of public statements and reinforcement of publicity are added. At the restoration stage, initial status response direction, response organization management, emergency response measures, and probation and restoration activities are implemented. Table 2 shows the application function description for the situation response.

\begin{tabular}{|c|c|c|c|}
\hline Level 1 & Level 2 & Level 3 & Description \\
\hline \multirow[t]{2}{*}{$\begin{array}{l}\text { Situation } \\
\text { response }\end{array}$} & $\begin{array}{l}\text { Response } \\
\text { level } \\
\text { selection }\end{array}$ & & $\begin{array}{l}\text { Selecting response } \\
\text { level: normal, } \\
\text { attention, } \\
\text { attention, alert, } \\
\text { severe, restoration }\end{array}$ \\
\hline & Response & & $\begin{array}{l}\text { Directing } \\
\text { response action }\end{array}$ \\
\hline
\end{tabular}

Table 2. Description of application function for real-time volcanic situation response

The sub-function of the eruption scenario function (Level 1) is very similar to that of the situation response function. However, the eruption scenarios are different from the real-time simulations, and the purpose is to show the diffusion scenario most similar to the current situation among the database that was pre-calculated and stored simultaneously with the volcanic eruption. Thus, the scenario selection function was added to Level 2. The sub-functions of the scenario selection function will be explained in detail in Section 3.2. Diffusion information, damage prediction, and analysis report functions in Level 2 are the same as the situation response function. Table 3 shows the application function description for eruption scenarios.

\begin{tabular}{|c|c|c|c|}
\hline Level 1 & Level 2 & Level 3 & Description \\
\hline \multirow{6}{*}{$\begin{array}{l}\text { Eruption } \\
\text { scenarios }\end{array}$} & \multirow{3}{*}{$\begin{array}{l}\text { Scenarios } \\
\text { selection }\end{array}$} & $\begin{array}{l}\text { 1st similar } \\
\text { scenario }\end{array}$ & \multirow{3}{*}{$\begin{array}{l}\text { Displaying most } \\
\text { similar scenarios } \\
\text { based on } \\
\text { weather status }\end{array}$} \\
\hline & & $\begin{array}{l}\text { 2nd similar } \\
\text { scenario }\end{array}$ & \\
\hline & & $\begin{array}{l}\text { 3rd similar } \\
\text { scenario }\end{array}$ & \\
\hline & $\begin{array}{l}\text { Diffusion } \\
\text { information }\end{array}$ & \multirow{3}{*}{\multicolumn{2}{|c|}{$\begin{array}{l}\text { same with real-time volcanic } \\
\text { disaster prediction }\end{array}$}} \\
\hline & $\begin{array}{l}\text { Damage } \\
\text { prediction }\end{array}$ & & \\
\hline & $\begin{array}{l}\text { Analysis } \\
\text { Report }\end{array}$ & & \\
\hline
\end{tabular}

Table 3. Description of application function for eruption scenarios

\subsection{Architecture reengineering for improving accuracy}

As analyzed in Chapter 2, the system upgrade requirements in terms of accuracy enhancement include the variations in the ash diffusion model and the addition of a similar scenario search function that considers the meteorological field.

As the diffusion model of volcanic ash, only FDR3D was used in VDRS V1.0. Because one diffusion model is not perfect in itself, it is necessary to consider various analytical models. There is a need to diversify a single prediction model into various ones (PUFF, LADAS, CMAQ, etc.) in the upgrading stage, and it is further necessary to add an ensemble model which utilizes all of them. One of the Level 3 functions of the real-time volcanic disaster prediction function (Level 1), the 
disaster selection function has sub-functions (Level 4) of volcanic ash, volcanic floods, pyroclastic flow, and volcanic mudflow. The volcanic ash function is reengineered to add a selection of various models. Table 4 shows the application function description for the type of disaster (Level 3) among the real-time volcanic disaster prediction (Level 1).

In VDRS V1.0, the eruption scenarios presented only one scenario that is the most similar. Moreover, similar meteorological fields were not included in the search for similar scenarios. To upgrade the architecture, it is necessary to reengineer it to present three similar scenarios with the highest degree of similarity by considering the meteorological field as new variables. Table 3 shows the results of the reengineer including the function to present three scenarios with the highest similarity as a sub-function of the scenario selection (Level 2) function.

\begin{tabular}{|l|l|l|}
\hline Level 3 & Level 4 & Description \\
\hline \multirow{4}{*}{$\begin{array}{l}\text { Disaster } \\
\text { type }\end{array}$} & $\begin{array}{l}\text { volcanic } \\
\text { ash }\end{array}$ & $\begin{array}{l}\text { Selecting analysis model: } \\
\text { FALL3D, PUFF, LADAS, } \\
\text { CMAQ }\end{array}$ \\
\cline { 2 - 3 } & $\begin{array}{l}\text { flood } \\
\text { fyroclastic } \\
\text { flow }\end{array}$ & \\
\cline { 2 - 3 } & $\begin{array}{l}\text { Volcanic } \\
\text { mudflow }\end{array}$ & \\
\hline
\end{tabular}

Table 4. Description of application function for disaster type function in real-time volcanic disaster prediction

\subsection{Architecture reengineering for spatial range and target disaster}

As previously mentioned, one of the user requirements of VDRS V2.0 is to extend the target volcano from one of Mt. Paektu to various volcanoes in East Asia. Accordingly, the volcanic positioning function that was not available in VDRS V1.0 should be added as a sub-function. This function should be placed in sub-functions of real-time volcanic disaster prediction (Level 1), disaster selection (Level 2), and eruption information (Level 3), which are shown in Table 1.

The user requirement for the expansion of the target disaster was to include volcanic floods, pyroclastic flow, and volcanic mudflow in addition to volcanic ash in the real-time disaster prediction simulation. It is necessary to reengineer the architecture in order to simulate disasters other than volcanic ash by disposing a disaster type (Level 3) as a sub-function of the disaster selection (Level 2), which is a sub-function of the volcanic disaster prediction function (Level 1). Table 1 shows the application function description, which is the result of the reengineer for expanding the target disaster.

\section{CONCLUSION}

In this paper, we reengineered the application architecture for upgrading volcanic disaster response system. First, we analyzed the application architecture of the existing system and the user requirements. Damage prediction of existing application architecture was required to change to task-oriented architecture because it is complex structure connected real-time simulation, eruption scenarios, and corresponding functions to one scenario. Furthermore, two additional functional requirements to enhance the analysis accuracy and additional functional requirements for space and disaster target expansion have been derived. The architecture was reengineered to reflect these requirements. The results of the reengineer were expressed in terms of the application system structure and the application functional description. In the structure of application system, real-time simulation, eruption scenarios, and corresponding functions were moved to Level 1 and the sub-functions were reorganized. Based on the changed application system structure, three functions in Level 1, 10 functions in Level 2, 9 functions in Level 3, and 4 functions in Level 4 are allocated and each task function description was derived. The result of the reengineer can be used to derive the application module design and the detailed description from the viewpoint of the designer in the future.

\section{ACKNOWLEDGEMENTS}

This research was supported by a grant [MOIS-DP-2015-07] through the Disaster and Safety Management Institute funded by Ministry of the Interior and Safety of Korean government.

\section{REFERENCES}

Bengtsson, P., and Bosch, J., 2018. Scenario-based Software Architecture Reengineering, Proceedings of 5th International Conference on Software Reuse, https://pdfs.semanticscholar.org/ba52/048ba99147b77327642ba cb2f2d6ade870e6.pdf (Jan. 8. 2018)

Cha, J., Kim, C., and Yang, Y., 2003. Architecture Based Software Reengineering Approach for Transforming from Legacy System to Component Based System through Applying Design Pattern, The Proceedings of SERA 2003, pp.266-278.

Youn, J., 2008. Enterprise Architecture for Linking Administrative Affairs and Spatial Information, Journal of Korean Society for Geospatial Information System, 16(3), pp.95-103.

Kim, J., and Kang, S., 2009. Case studies: Software Architecture Reengineering for Function Extensibility, The Proceedings of 2009 KCSE Conference, http://koasas.kaist.ac.kr/bitstream/10203/22098/1/2009\%20\%E A\%B9\%80\%EC\%A0\%95\%ED\%98\%B8\%20-

\%20KCSE_2009\%20-

$\% 20 \% \mathrm{EC} \% 8 \mathrm{~B} \% \mathrm{~A} 4 \% \mathrm{EC} \% \mathrm{~A} 0 \% 9 \mathrm{C} \% \mathrm{EC} \% 82 \% \mathrm{AC} \% \mathrm{~EB} \% \mathrm{~A} 1 \% 8$ $0-$

$\%$ ЕА $\%$ В $\%$ В $\%$ ЕВ $\% 8$ А $\% 5 \%$ ED $\% 99 \% 95 \%$ ЕC $\% 9 \mathrm{E} \%$ А5\%Е C\%84\%B1\%EC\%9D\%84_\%EC\%9C\%84\%ED\%95\%9C_\%EC \%86\%8C\%ED\%94\%84\%ED\%8A\%B8\%EC\%9B\%A8\%ЕC\%9 6\%B4_\%EC\%95\%84\%ED\%82\%A4\%ED\%85\%8D\%EC\%B2\% 98_\%EC\%9E\%AC\%EC\%84\%A4\%EA\%B3\%84_.pdf February 2018)

Kim, H., and Choi, H., 2013. A Design of Platform Architecture for Operating Integrated Volcanic Disaster Response System, The Proceedings of 2013 KSHM Conference, pp.414-419.

Kim, T., and Youn, J., 2014. A Study on the IT-Based Response System Development for Mt. Baekdu Volcanic Disaster, Journal of the Korean Association of Geographic Information Studies, 17(1), pp.13-23. 
Youn, J., Kim, H., Kim, S, and Kim, T., 2016. 3D Visualization Techniques for Volcanic Ash Dispersion, Journal of the Korean Society for Geospatial Information Science, 24(1), pp.99-107.

Youn, J., and Kim, T., 2016. 3D Visualization of Volcanic Ash Dispersion Prediction with Spatial Information Open Platform in Korea, The International Archives of the Photogrammetry and Remote Sensing and Spatial Information Science, XL1B8(XXIII), pp.185-190.

Youn, J., and Kim, C., 2015. System Implementation Plan for Applying Spatial Information to Road Occupation Permit Administrative Works, Journal of the Korea AcademiaIndustrial cooperation Society, 16(6), pp.4208-4215. 